\title{
Non-sensitising air pollution at workplaces and adult-onset asthma in the beginning of this millennium
}

Pål Graff, Mats Fredrikson, Pia Jönsson and Ulf Flodin

\section{Linköping University Post Print}

N.B.: When citing this work, cite the original article.

The original publication is available at www.springerlink.com:

Pål Graff, Mats Fredrikson, Pia Jönsson and Ulf Flodin, Non-sensitising air pollution at workplaces and adult-onset asthma in the beginning of this millennium, 2011, International Archives of Occupational and Environmental Health, (84), 7, 797-804.

http://dx.doi.org/10.1007/s00420-011-0671-2

Copyright: Springer Verlag (Germany) http://www.springerlink.com/

Postprint available at: Linköping University Electronic Press http://urn.kb.se/resolve?urn=urn:nbn:se:liu:diva-72824 
Non-sensitising air pollution at workplaces and adult onset asthma in the beginning of this millennium

\section{Authors' affiliations}

Pål Graff (PhD) \& Ulf Flodin (MD): Centre of Occupational and Environmental Medicine, University Hospital, SE-58185 Linköping, Sweden.

Mats Fredrikson (PhD), Pia Jönsson (BSc): Department of Clinical and Experimental Medicine, Linköping University, SE-58183 Linköping, Sweden

Correspondence: Pål Graff, Centre of Occupational and Environmental Medicine, University Hospital, SE-58185Linköping, Sweden. pal.graff@lio.se

Fax +4613145831

Keywords: low level exposure, non-sensitising, irritants, asthma, workplace 
Non-sensitising air pollution at workplaces and adult onset asthma

\begin{abstract}
Purpose This case-control study was undertaken to elucidate the controversy concerning whether low level, long-term exposure to non-sensitising air pollution at workplaces may cause asthma.
\end{abstract}

Methods A case-control study of 192 adult onset asthma cases aged 20 - 65 years and 323 controls was conducted in the southeast of Sweden. Cases were identified from computerised registers from the region, diagnosed 2000-2004 and diagnoses were confirmed via medical files. Referents were randomised from the population register of the region. Exposure was monitored by a 16-page questionnaire. Special attention was devoted to identifying and in the final analyses excluding subjects exposed to sensitising agents.

Results Three years or more of occupational exposure to air pollution from dust, smoke, fumes or vapours before the year of diagnosis by analyses adjusting for age yielded an increased risk for asthma $(\mathrm{OR}=2.3,95 \% \mathrm{CI} 1.2-4.2)$ in males, while in females no risk was seen. In a multiple logistic regression analysis in males without allergy in childhood, a significant risk was seen $(\mathrm{OR}=2.8,95 \% \mathrm{CI} 1.07-7.4)$, when subjects exposed to identified allergens were excluded. In females no excess risk was observed from occupational air pollution.

Conclusion The results of this study support an association between occupational exposure to low level non-sensitising air pollution and adult onset asthma in males. 
Non-sensitising air pollution at workplaces and adult onset asthma

\section{Introduction}

The traditional definition of occupational asthma, is asthma arising from workplace exposure to airway sensitising agents in a previously unsensitised person (Chan-Yeung and Lam 1986). In 1985 Brooks et al., founded the concept of RADS, i.e. reactive airway dysfunction syndrome (Brooks et al. 1985). This can be described as a new onset of an -irritant-induced asthma within 24 hours after a single exposure to high concentrations of a respiratory irritant gas, fumes or vapour (Tarlo 2003). Subsequently a discussion has arisen about the existence of a low-level RADS (Kipen et al. 1994; Tarlo 2000), as well as the idea of a "not so sudden" irritant-induced asthma (Banks 2001).

There is insufficient evidence of new-onset, work-related asthma due to chronic low-level exposures to irritants according to Mapp et al. (Mapp et al. 2005). Francis et al. (2007) find only weak evidence for the existence of a low dose, irritant-induced asthma (Francis et al. 2007). Well established irritating chemical agents such as chlorine, ozone, ammonia, strong acids and sulphur dioxide are discussed in the context of low level RADS.

However, an increasing number of papers find an association between long-term, low level exposure to air pollution, including not only the group of well recognized airway irritants but also dust, fumes and vapours of different kinds, sensitisers excluded, at workplaces and adult onset asthma. For example in some Finnish studies an increased risk for asthma was observed in non-sensitising branches such as mining and quarrying (Karjalainen et al. 2001), also for construction workers, welders, plumbers and asphalt roofing workers (Karjalainen et al. 2002b), wood-processing industry workers (Heikkila et al. 2008) and industrial cleaners (Karjalainen et al. 2002a).

In a Norwegian cohort study, the physician-diagnosed asthma risk was increased for individuals who ever were exposed to occupational dust or fumes, $\mathrm{OR}=1.6,95 \% \mathrm{CI} 1.01-2.5$ 
Non-sensitising air pollution at workplaces and adult onset asthma

(Eagan et al. 2002). Household cleaners exposed to chlorine and ammonia in a Spanish case control study had a ten-fold increased odds ratio for asthma. These chemicals are irritating and the authors interpret their results as not being caused by sensitising agents (MedinaRamon et al. 2005). Also the relatively low level of ambient irritating air pollution from traffic exhausts in cities in Sweden (Modig et al. 2009) and 14 other cities in the European Community (Jacquemin et al. 2009) give an excessive risk for asthma.

Altogether these papers indicate that exposure to low levels of non-sensitising dust, fumes or vapour are risk factors for adult onset occupational.

The present paper is a third case-control study from our research group concerning exposure to every day air pollution in Swedish working life as a risk factor for contracting asthma. Our first study was performed on cases diagnosed 1950 - 1990 in two communities with dominating wood industry (Flodin et al 1996), the second study encompassed cases of asthma diagnosed 1960 - 1997 in a metal industry dominated community ( Flodin et al 2004). Those two studies found an significant excess risk for asthma in subjects having worked for at least tree years in non sensitising air polluted workshops. The present study encompassed cases having incident asthma in 2000-2004, thus in recent time, when working environment as for air pollution have improved greatly compared to earlier decades. The question of the present study is if air quality in Swedish working life in present time is good enough for avoiding excess risk for contracting irritant induced asthma. 
Non-sensitising air pollution at workplaces and adult onset asthma

\section{Material and methods}

\section{Cases}

Cases of asthma were collected through a computerized patient register including all of the county of Kalmar in the southeast of Sweden. In the year 2000 that region had 132000 inhabitants aged 20-65 years. All cases appearing in the diagnosis register with an asthma diagnosis in the years 2000-2004 were included in the search process. The second step in the selection process was to scrutinize the computerised medical files of those subjects having an asthma diagnosis. Criteria for inclusions in the study were: (i)living in the county of Kalmar when diagnosed with an asthma, (ii)age at the year of diagnosis 20-65 years (iii)not having worked abroad, (iv)born in Sweden, (v)not having asthma in childhood, (vi)no other lung disorders such as COPD (chronic obstructive pulmonary disorder) or emphysema.

The diagnosis of asthma was given by general practitioners or specialists in internal medicine using Peak Flow registrations during a two-week period, indicating a variability of at least $20 \%$, or forced expiratory volume during one second $\left(\mathrm{FEV}_{1} \mathrm{~S}\right)$, or reversibility tests with at least $12 \%$ improvement in $\mathrm{FEV}_{1} \mathrm{~S}$ after inhalation of beta agonists or steroid treatment, or decreased air flow registered as a fall in $\mathrm{FEV}_{1} \mathrm{~S}$ by at least $12 \%$ in a metacholine test. Those criteria are the ones used in clinical practice in Sweden. Besides which, the patients had to present a typical history of asthma including repeated episodes of clinically significant airway obstructions combined with rhonchi at physical examinations. Cases of chronic bronchitis, emphysema and lung disorders other than pure asthma were excluded. Four hundred and thirty one cases of asthma fulfilled the diagnostic criteria and were sent a 16-page postal questionnaire. Three hundred and ten cases (72\%) completed the questionnaire and returned it after two reminders. To confirm that the year of asthma diagnosis was correctly understood by us, we sent a second questionnaire after information about the subjects' exposures had been 
Non-sensitising air pollution at workplaces and adult onset asthma

obtained from them. In the second questionnaire we specifically asked for the year of asthma diagnosis. Thereby 78 subjects were excluded since their asthma had started earlier than year 2000. Twenty six subjects were excluded since they had asthma in childhood. Eight individuals had recovered from asthma some years before replying to the questionnaire and six subjects were excluded since they hade been working abroad for a long period. Thus 192 cases remained for analysis.

\section{Referents}

The referents were randomised from the population registry of the county council of Kalmar to which everyone living in the region is affiliated. For each primarily identified case, one referent was drawn from the population registry. (Primarily cases were those appearing in the computerised medical register of the county council, before we had scrutinised the diagnostic criteria, see Cases above). Criteria for selection were: not having been diagnosed for asthma and aged 20-65 the same year as the diagnosis of asthma was given for the primarily respective case. To exclude asthmatics among referents we used the answers of the questionnaire concerning diagnoses and drug intake. No matching for gender was performed. Four hundred and eighty three indented referents were sent a 16-page questionnaire, which was completed by 357 subjects (74\%) after two reminders, while 126 refused to participate. One referent was rejected by us since born abroad, one was addicted to narcotics which prevented him from working, four subjects had been working abroad for a long period which meant difficulties in classifying their exposure situation, fourteen turned out to have had asthma as a child or in adolescence, which might have influenced their choice of occupation, two had the diagnosis of COPD and two subjects were not able to be reached for complementary information in the questionnaires. Ten subjects were excluded since they used beta 2 agonists and therefore were not guaranteed free from lung disorders. In all, 34 referents 
were excluded, thus 323 useable referents then remained. Since the asthma cases were diagnosed between 2000 and 2004 and we were interested in exposures prior to the onset of asthma, taken as the year of diagnosis, an anchor point in time had to be found for the referents. This was solved by assigning every referent a pseudo year of diagnosis, the same as respective primarily selected case. There were 115 female cases (59.9\%) and 77 males (40.1\%) out of the 192 cases and 153 females (47.4\%) and $170(52.6 \%)$ males out of the 323 referents. Mean age of cases at the year of their diagnosis was 41 years and corresponding anchor point year in time for referents was 46 years.

From the questionnaire we gained information about the subjects' ${ }^{\prime}$ allergies in childhood or adolescence and smoking habits.

\section{Assessment of exposure}

Information on exposure was obtained with a 16-paged questionnaire about exposures lasting at least one year in a time window restricted to ten years preceding the year of asthma diagnosis and with regard to workplace conditions including e.g. job titles, work tasks, significant or disturbing occurrences of dust, fumes, vapours and passive smoking, moisture damage and mould in buildings. There were specified questions on animal contact and 25 specified occupational exposures, for example specific questions about flour, isocyanates, latex rubber, methyl metacrylate, welding, allergenic metals, soldering, lubricating oils, spray painting, water based paints, organic solvents, hair dressing chemicals, chimney sweeping, super fast glues, irritants such as chlorine gas, ozone, sulphur dioxide or ammonia. The questions were similar to those that had been used in a previous study (Flodin and Jonsson 2004). By means of the questionnaire we intended to identify exposures to sensitising agents occurring in our sampled population. Thereby we identified subjects exposed to flour dust, 
Non-sensitising air pollution at workplaces and adult onset asthma

farming, latex, cyanoacrylates, isocyanates, chromium, nickel, cobalt and salts from aluminium.

We classified the job titles into categories, i.e. clean or polluted, based on the judgement of a hygienist (PG) and based on knowledge of the regional workplace exposure situations about dust, fumes, vapours reported in connection with various job titles. Dust and fumes were merged to an exposure category denoted particles. An exposure matrix was created according to the various job titles. Thus the following work titles were classified as polluted.

Exposed to particles: art gallery and museum curator, artist in ceramics and textiles, building caretakers, cabinetmakers, carpenters and joiners, cars and industrial painters, cement finishers and terrazzo workers, cleaners and related workers, construction workers not elsewhere classified, decorators, glass and ceramics workers, road transport workers, farm workers, furnace men and kiln men, metal and glass formers, cutters, grinders and finishers, glaziers, livestock workers, loggers and other forestry workers, machine-tool operators, mechanics-repairmen, metal workers, moulders and core makers, operators of construction machinery, painters and paperhangers, construction and maintenance workers, paper makers, paper-pulp preparers, patternmakers, markers and cutters, plastics-product makers, sanitation workers, sawyers and woodworking machine setters and operators, sewers and embroiderers, sheet-metal workers, teachers in arts and practical education, upholsterers and related workers and welders and flame cutters.

Exposed to vapours: barbers, hairdressers, beauticians and related workers, cars and industrial painters, cleaners and related workers, engravers, printers, fitter-assemblers and machine assemblers, metal furnace men, launderers, dry cleaners and pressers, machine-tool operators, mechanics-repairmen, moulders and core makers, painters and paperhangers, construction and maintenance workers, petroleum-refining workers, plastics-product makers, sanitation 
workers, stationary engine and related equipment operators and upholsterers and related workers.

Our intention in this study is to evaluate the hypothesis that non-sensitising air pollution at work might be a risk factor for adult onset asthma. Thereby we have strived to identify exposures without sensitising properties. Consequently in the final analyses we excluded subjects exposed to flour dust, farming, latex. cyanoacrylates, isocyanates, chromium, nickel, cobalt and salts from aluminium according to their answers in the questionnaire.

\section{Ethics.}

This project was approved by the Regional Ethical Research Committee of the University Hospital of Linköping in 2002, diary number 02-317.

\section{Statistics}

Exposure up to the year of diagnosis, given by a physician, was considered for cases and the corresponding anchor point in time for respective referents as well. A minimum exposure time requirement of three years with end of exposure null to two years before the year of diagnosis for asthma was applied for all kinds of exposures. Unexposed subjects were those who did not have any exposure to the studied agents at all. Subjects not fulfilling the exposure demands, see above, were excluded in the statistical analyses. We calculated odds ratios as a measure of relative risk for all single exposures that had lasted for at least three years, after adjustment for age with logistic regression. A lag time demand of null to two years from the end of exposure until year of diagnosis was used, since many asthmatics have had their disorder some years before they get their diagnosis and might change their jobs because of their asthmatic symptoms. Since the occupational exposures differed between males and females, analyses were performed separately for both genders. This is in agreement with 
Non-sensitising air pollution at workplaces and adult onset asthma

recommendations taking gender differences in exposure into account (Kennedy and Koehoorn 2003). Logistic regression was also used for the other analysis in order to check for potential confounders. In the final multiple logistic regression analysis, subjects who in the questionnaire stated themselves as exposed to known occupational asthma-associated allergens were excluded, but not subjects exposed to mould at their workplace, since the mechanism of the latter seems to be a nonspecific inflammatory response (Taskinen et al. 2002; Lander et al. 2001). All analyses were carried out with Stata v 10.1 (StataCorp, College Station, TX, USA). A probability value of $0.05(5 \%)$ was considered as statistically significant. 
Non-sensitising air pollution at workplaces and adult onset asthma

\section{Results}

Our study includes $60 \%$ females and $40 \%$ males. The gender balance in the population is even in age $20-65$ years in the county of Kalmar, which is our study base.

Males.

In males occupational exposure to particles, i.e. dust or fumes resulted in increased odds ratios for asthma $(\mathrm{OR}=2.3,95 \% \mathrm{CI} 1.2-4.2)$, see Table $1 \mathrm{~A}$. The merged air pollution variable including dust, fumes and vapours, involved a similar risk $(\mathrm{OR}=1.9,95 \%$ CI 1.03 - 3.4). Active smoking and passive smoking at work did not lead to a significantly increased risk for asthma, nor did ever smoking including current- and ex-smokers.

In order to take care of possible confounders we used multiple logistic regression analysis.

Since we were interested in non-sensitising asthma, we excluded subjects exposed to allergens. Thereby 137 males were excluded.

\section{Table 1 A}

Exposures of interest for asthma in males exposed three years or more with an end of exposure null to two years preceding the year of asthma diagnosis and corresponding time period for referents. Exposure assessment by Job exposure matrix = $(\mathrm{JEM})$ or by subjects own statements $=(\mathrm{S})$. Odds ratios are adjusted for age by logistic regression.

$\begin{array}{lllll}\text { Exposure } & \text { Number } & \text { of } & \text { OR } & \text { 95\%C.I. } \\ & \text { Cases } & \text { Referents } & & \\ & \mathrm{n}=77 & \mathrm{n}=170 & & \\ & 40 & 59 & 2.3 & 1.2-4.2 \\ \text { Occupational exposure to particles (JEM) } & 18 & 27 & 1.5 & 0.7-3.0 \\ \text { Occupational exposure to vapour (JEM) } & 18 & 67 & 1.9 & 1.03-3.4 \\ \text { Occupation exposure to air pollution (JEM) } & 41 & 19 & 1.4 & 0.6-3.0 \\ \text { Allergy in childhood (S) } & 13 & 26 & 0.6 & 0.2-1.5 \\ \text { Active smoking (S) } & 7 & 34 & 0.96 & 0.4-1.9 \\ \text { Ever smoking (S) } & 16 & 23 & 1.2 & 0.5-2.6 \\ \text { Passive smoking at work (S) } & 15 & 9 & 2.4 & 0.90-6.1 \\ \text { Moisture or mould at workplace(S) } & 10 & 9 & & \end{array}$


Occupational exposure to the merged air pollution category including dust, fumes and vapours at work brought a significantly increased risk ( $\mathrm{OR}=2.8,95 \% \mathrm{CI} 1.07-7.3)$ in males without allergy in childhood according to answers in the questionnaire, see Table $1 \mathrm{~B}$. In males, who had allergic symptoms in childhood, exposure to the merged occupational air pollution yielded an insignificantly increased asthma risk $(\mathrm{OR}=4.9,95 \% \mathrm{CI}$ 0.27- 89). Odds ratios for ever smoking and allergy in childhood were not significantly increased, see Table $1 \mathrm{~B}$

\section{Table 1 B}

Logistic odds ratios for exposures of interest in males according to logit $\mathrm{f}(\mathrm{y})$ case/referent $=$ $1.43+1.31$ (childhood allergy) +1.03 (occupational air pollution) +1.60 (childhood allergy)(occupational air pollution) +0.39 (ever smoking) -0.003 (age). Subjects exposed to occupational allergens of significance in this material; i. e. flour dust, farming, latex, chromium, nickel, cobalt, alumina salt, cyanoacrylates and isocyanates $(n=137)$ are excluded. The included number of cases and controls were 33 and 77 respectively.

\begin{tabular}{|c|c|c|}
\hline Exposure & Logistic OR & $95 \%$ C. I. \\
\hline $\begin{array}{l}\text { Occupational air pollution in } \\
\text { subjects without allergy in } \\
\text { childhood }\end{array}$ & 2.8 & $1.07-7.4$ \\
\hline $\begin{array}{l}\text { Occupational air pollution } \\
\text { in subjects with allergy in } \\
\text { childhood. }\end{array}$ & 4.9 & $0.2-89.0$ \\
\hline $\begin{array}{l}\text { Allergy in childhood without } \\
\text { occupational air pollution }\end{array}$ & 3.7 & $0.8-15$ \\
\hline Ever smoking & 1.5 & $0.5-4.1$ \\
\hline
\end{tabular}

\section{Females.}

In females only occupational use of latex-gloves by job exposure matrix yielded an increased relative risk for asthma, see Table $2 \mathrm{~A}$.

In the multiple logistic regression analyses, we excluded subjects with exposure to allergens identified in our material. Thereby 124 females were excluded.

No occupational exposure or air pollution at workplaces variables brought about any statistically significant risk, see Table 2 B. 


\section{Table 2 A}

Exposures of interest for asthma in females exposed three years or more with an end of exposure null to two years before the year of asthma diagnosis and corresponding time period for referents. Exposure assessment by Job exposure matrix $=(\mathrm{JEM})$ or by subjects own statements $=(\mathrm{S})$. Odds ratios were adjusted for age by logistic regression.

\begin{tabular}{|c|c|c|c|c|}
\hline Exposure & $\begin{array}{l}\text { Number } \\
\text { Cases } \\
n=115\end{array}$ & $\begin{array}{l}\text { of } \\
\text { Referents } \\
n=153\end{array}$ & OR & $95 \%$ C.I. \\
\hline Occupational exposure to particles (JEM) & 15 & 26 & 0.6 & $0.2-1.2$ \\
\hline Occupational exposure to vapour (JEM) & 9 & 16 & 0.8 & $0.3-2.0$ \\
\hline Occupation exposure to air pollution (JEM) & 19 & 36 & 0.6 & $0.3-1.1$ \\
\hline Allergy in childhood $(S)$ & 28 & 17 & 2.0 & $0.98-3.9$ \\
\hline Active smoking (S) & 24 & 33 & 0.97 & $0.5-1.8$ \\
\hline Ever smoking (S) & 34 & 48 & 0.94 & $0.5-1.6$ \\
\hline Passive smoking at work $(\mathrm{S})$ & 15 & 13 & 1.6 & $0.7-3.7$ \\
\hline Latex gloves (JEM) & 9 & 6 & 3.0 & $1.00-9.1$ \\
\hline Moisture or mould at workplace (S) & 6 & 6 & 1.3 & $0.3-4.4$ \\
\hline
\end{tabular}

\section{Table 2 B}

Logistic odds ratios for exposures of interest in females, according to logit $\mathrm{f}(\mathrm{y})$ case/referent $=1.55+0.68$ (childhood allergy) -0.85 (occupational air pollution) +1.03 (childhood allergy)(occupational air pollution) +0.22 (ever smoking) +0.046 (age) .

Subjects exposed to occupational allergens of significance in this material; i. e. flour dust, farming, latex, chromium, nickel, cobalt, alumina salts, cyanoacrylates and isocyanates $(n=124)$ are excluded. The included number of cases and controls were 60 and 84 respectively.

Exposure

Occupation air pollution

in subjects without allergy in childhood

Occupational air pollution in subjects with allergy in childhood
Logistic OR $95 \%$ CI.

$0.4 \quad 0.1-1.2$

2.8

$0.3-28$

2.0

$0.7-5.4$

occupational air pollution

Ever smoking 
Non-sensitising air pollution at workplaces and adult onset asthma

\section{Discussion}

Comments on the results: _The excess number of females to males in our material reflects the increased risk for asthma in adult women. This phenomenon is described from the US (Schatz and Camargo 2003; De Marco et al. 2002). Thus the asthma case material recruited for our study with a female dominance probably reflects a correct catchment procedure.

The main result of this study is that three years or more of occupational exposure to nonsensitising air pollution, especially to particles i.e. dust and fumes, increases the risk for asthma in males, but not in females. There are some possible explanations for an effect seen only in males: Males' occupations expose them to air pollution to a greater extent than for females. In a population survey encompassing some six thousand inhabitants in a neighbouring county, up to 20 per cent of males stated themselves as being exposed to dust, fumes or vapour, whilst only some single per cent of the females stated themselves as exposed to the same agents (Ekberg et al. 2000). The number of female cases exposed to air pollution for at least three years was rather low, 19 women.(Table $2 \mathrm{~A})$. The lower risk for asthma in exposed females is not statistically significant.

In our earlier studies on work related asthma exposed females were at risk for asthma. However knowledge about the possible harmful effect from exposure to air pollution might be more widespread in these days than earlier, and workers suffering from symptoms from the airways might change job to avoid their symptoms. Especially women are apt to quit job when disturbed (Le Moual et al. 2008; Lea et al. 1999).

The male dominant risk for occupational asthma has earlier been reported from California , but the author does not give any explanation for the gender difference (Reinisch et al. 2001). As the cases in this study were restricted to individuals that received their diagnosis between 2000-2004 and the exposure time window was set to ten years before diagnosis, we have observed the results of exposure from 1990 and later. This means that exposure levels in 
Non-sensitising air pollution at workplaces and adult onset asthma

Swedish working life still might expose male workers to air pollutants that increase the risk of asthma. According to analyses of exposure time demand in an earlier study (Flodin and Jonsson 2004), the greatest risk for asthma occurred in a time window three years from start of exposure, not shown in tables. This might be understood as that susceptible individuals react with airway inflammation within a three year period, whilst individuals who are less susceptible do not react despite longer exposure. Only three referents and no case stated themselves as exposed to high levels of irritating agents in accidents. Thereby we can exclude RADS as a part of asthma diagnosis in this material.

The etiological fraction from exposure to air pollution at workplaces in males in the present study is $25 \%$ (fraction of exposed cases $\mathrm{x}(\mathrm{OR}-1) / \mathrm{OR}$; i.e.41/77x $(1.9-1) / 1.9)$ (Rothman and Greenland 1998). Those figures include all kinds of adult onset asthma, i.e. sensitising and non-sensitising asthma. This etiological fraction lies within the range $(8.6-44 \%$, mean $18.9 \%$ ) reported from 17 adult onset asthma studies in a review paper (Toren and Blanc 2009). The etiologic fraction of asthma in this study in the subgroup of non- sensitising agents is $15 / 33 \times(2.8-1) / 2.8=29 \%$.

Smoking was no risk indicator in this study, which is in conflict with results from our first material (Flodin et al. 1996; Flodin et al. 1995). This might be due to the public awareness in Sweden about the adverse health effects from smoking, meaning that subjects getting symptoms from their airways give up smoking within a short period and, thus never have a career as a smoker. That explanation is supported by the fact that smoking is getting less common in Sweden. In $198530 \%$ of males and $26 \%$ of women smoked daily, while in 2000 $17 \%$ of males and $20 \%$ of females are daily smokers (Helmfrid et al. 2009). The effect from exposure to occupational air pollution in this material was significantly increased in males without allergies in childhood. Similar findings were made by Reinisch (Reinisch et al. 2001). Moreover, in their study $70 \%$ of all new onset asthma cases were associated with exposure 
Non-sensitising air pollution at workplaces and adult onset asthma

not known to be sensitising. That observation gives support to our results and to the concept of non-sensitising asthma from low level exposure to irritating agents such as dust, fumes and vapour. Interestingly, outside working life, athletes such as swimmers who are exposed to chlorine and cross-country skiers inhaling cold air are observed as having an increased incidence for asthma (Bougault et al. 2009). Again, the exposure of these groups of athletes seems to be non-sensitising.

\section{Methodology:}

The asthma cases were recruited from the healthcare units of the county of Kalmar in the southeast of Sweden. The county has 31 publicly financed healthcare units manned by general practitioners, of which three units were not willing to participate. The asthma diagnosis in Sweden is most often given by general practitioners in the public healthcare system. Thereby we were able to include the greater majority of asthma cases in the investigated county and the risk for selection bias of cases is minimal.

To be included in this study cases had to fulfil specific criteria, mentioned in Material and Methods. Thereby we consider the demand of a diagnostic quality is fulfilled. The referents were selected by using the population register of the county council, which includes all inhabitants of the catchment area, thus no selection bias would occur for the referents. The response rate was $72 \%$ for cases and $74 \%$ for referents, which are acceptable results. The job titles, stated by the subjects themselves, were classified as air polluted according to the judgements of our occupational hygienist. But some information had to be taken directly from the answers in the questionnaires, i.e. exposure to occupational allergens occurring in our region as well as smoking habits, allergies in childhood and moisture or mould in the workplaces and homes. Ideally, we would have visited the workplaces and homes to form a professional judgement of their exposures including to sensitising agents, but this was not 
Non-sensitising air pollution at workplaces and adult onset asthma

possible within our economical frames. The focus of interest in this study is the role of non sensitising agents as a cause for asthma. Therefore we have excluded subjects exposed to allergens bringing increased risks for asthma in this material, see "Assessment of exposure" in the sector of "Methods".

Synthesis with previous knowledge

This is the third study from our research group with the aim of evaluating the possible role of non-sensitising occupational air pollution in increasing the risk for adult onset asthma. Earlier studies have included subjects with asthma diagnosed from 1950-1989 (Flodin et al. 1996) and 1960-1997 (Flodin and Jonsson 2004). This study encompassed diagnoses from 20002004. The study population is from the same region in Sweden (the southeast), but now includes a greater number of communities. The results in this study are less pronounced than in the earlier ones as air-polluted work yielded an increased risk for asthma only in males. In earlier studies the risk was seen for both genders. An explanation to this might be increased air quality in Swedish working life during the decades.

The results of this study are in accordance with some other recent studies, mentioned above. Altogether these papers indicate that exposures to non-sensitising agents are risk factors for adult onset occupational asthma. However, despite the primarily collected asthma material is rather great, 431 identified cases, in the final analyse only 47 male and 31 female cases remained for the final analyse in table $1 \mathrm{~B}$ respective $2 \mathrm{~B}$. The results therefore of course is only indicative for an association between irritating air pollution in occupational settings and asthma, seen in males in our present material.

The mechanisms behind non-sensitising asthma are unknown (Mapp et al. 2005).Never the less, interestingly, in underground iron ore miners exposed to diesel exhausts and dusts, an 
Non-sensitising air pollution at workplaces and adult onset asthma

increased inflammatory activity has been shown by means of induced sputum. Concentrations of fibronectin, metalloproteinase- 9 and interleukin-10 as well as inflammatory cells were augmented also after a 4-week holiday period (Adelroth et al. 2006). This indicates that an inflammatory process in the mucous membranes of the airways is triggered by air pollution in everyday situations for workers in air polluted occupations.

In miners and construction workers, dust exposure tends to increase the incidence for chronic bronchitis (Hedlund et al. 2006; Bergdahl et al. 2004) as well as for asthma (Hedlund et al. 2006; Karjalainen et al. 2002a). An interesting question is why some individuals show higher risks of developing asthma and yet others develop chronic bronchitis after exposure to irritants.

\section{Concluding remarks}

This population-based, case-control study including cases diagnosed during this millennium and with its focus on exposures occurring from 1990 onwards has found an approximately doubled risk from occupational exposures to non-sensitising air pollution to bring about adult onset asthma in males.

Acknowledgements This study was funded by the Swedish Cancer and Allergy Foundation and Forss (Medical Research Council of Southeast Sweden).

The authors would like to thank the general practitioners in the county council of Kalmar for assistance, especially Drs Bengt Öberg, Staffan Skobe and Roger Lindbergh and Mrs Marie Mobäck for data collection support. We would also like to thank Anna-Lena Hällsten for great administrative support in this study.

Conflict of interest The authors declare that the have no conflict of interest. 


\section{References}

Adelroth E, Hedlund U, Blomberg A, Helleday R, Ledin MC, Levin JO, Pourazar J, Sandstrom T, Jarvholm B (2006) Airway inflammation in iron ore miners exposed to dust and diesel exhaust. Eur Respir J 27 (4):714-719

Banks DE (2001) Workplace irritant exposures: Do they produce true occupational asthma? Curr Opin Allergy Clin Immunol 1 (2):163-168

Bergdahl IA, Toren K, Eriksson K, Hedlund U, Nilsson T, Flodin R, Jarvholm B (2004) Increased mortality in copd among construction workers exposed to inorganic dust. Eur Respir J 23 (3):402-406

Bougault V, Turmel J, St-Laurent J, Bertrand M, Boulet LP (2009) Asthma, airway inflammation and epithelial damage in swimmers and cold-air athletes. Eur Respir $\mathbf{J}$ 33 (4):740-746

Brooks SM, Weiss MA, Bernstein IL (1985) Reactive airways dysfunction syndrome (rads). Persistent asthma syndrome after high level irritant exposures. Chest 88 (3):376-384

Chan-Yeung M, Lam S (1986) Occupational asthma. Am Rev Respir Dis 133 (4):686-703

De Marco R, Locatelli F, Cerveri I, Bugiani M, Marinoni A, Giammanco G (2002) Incidence and remission of asthma: A retrospective study on the natural history of asthma in italy. J Allergy Clin Immunol 110 (2):228-235

Eagan TM, Gulsvik A, Eide GE, Bakke PS (2002) Occupational airborne exposure and the incidence of respiratory symptoms and asthma. Am J Respir Crit Care Med 166 (7):933-938

Ekberg K, Noorlind Brage H, Dasterri M (2000) Östgötens hälsa och miljö 2000 (in swedish), vol 00:1. Folkhälsovetenskapligt Centrum, County council of Östergötland, Sweden,

Flodin U, Jonsson P (2004) Non-sensitising air pollution at workplaces and adult onset asthma. Int Arch Occup Environ Health 77 (1):17-22

Flodin U, Jonsson P, Ziegler J, Axelson O (1995) An epidemiologic study of bronchial asthma and smoking. Epidemiology 6 (5):503-505

Flodin U, Ziegler J, Jonsson P, Axelson O (1996) Bronchial asthma and air pollution at workplaces. Scand J Work Environ Health 22 (6):451-456

Francis HC, Prys-Picard CO, Fishwick D, Stenton C, Burge PS, Bradshaw LM, Ayres JG, Campbell SM, Niven RM (2007) Defining and investigating occupational asthma: A consensus approach. Occup Environ Med 64 (6):361-365

Hedlund U, Jarvholm B, Lundback B (2006) Persistence of respiratory symptoms in exunderground iron ore miners. Occup Med (Lond) 56 (6):380-385

Heikkila P, Martikainen R, Kurppa K, Husgafvel-Pursiainen K, Karjalainen A (2008) Asthma incidence in wood-processing industries in finland in a register-based population study. Scand J Work Environ Health 34 (1):66-72

Helmfrid I, Graff P, Hellström L, Fredriksson M, Åkerlund A, Ståhlbom B (2009) Regional environmental-health report 2009 county of östergötland, jönköping and kalmar.

Jacquemin B, Sunyer J, Forsberg B, Aguilera I, Briggs D, Garcia-Esteban R, Gotschi T, Heinrich J, Jarvholm B, Jarvis D, Vienneau D, Kunzli N (2009) Home outdoor no2 and new onset of self-reported asthma in adults. Epidemiology 20 (1):119-126

Karjalainen A, Kurppa K, Martikainen R, Klaukka T, Karjalainen J (2001) Work is related to a substantial portion of adult-onset asthma incidence in the finnish population. Am $\mathrm{J}$ Respir Crit Care Med 164 (4):565-568

Karjalainen A, Martikainen R, Karjalainen J, Klaukka T, Kurppa K (2002a) Excess incidence of asthma among finnish cleaners employed in different industries. Eur Respir J 19 (1):90-95 
Karjalainen A, Martikainen R, Oksa P, Saarinen K, Uitti J (2002b) Incidence of asthma among finnish construction workers. J Occup Environ Med 44 (8):752-757

Kennedy SM, Koehoorn M (2003) Exposure assessment in epidemiology: Does gender matter? Am J Ind Med 44 (6):576-583

Kipen HM, Blume R, Hutt D (1994) Asthma experience in an occupational and environmental medicine clinic. Low-dose reactive airways dysfunction syndrome. J Occup Med 36 (10):1133-1137

Lander F, Meyer HW, Norn S (2001) Serum ige specific to indoor moulds, measured by basophil histamine release, is associated with building-related symptoms in damp buildings. Inflamm Res 50 (4):227-231

Le Moual N, Kauffmann F, Eisen EA, Kennedy SM (2008) The healthy worker effect in asthma: Work may cause asthma, but asthma may also influence work. Am J Respir Crit Care Med 177 (1):4-10

Lea CS, Hertz-Picciotto I, Andersen A, Chang-Claude J, Olsen JH, Pesatori AC, Teppo L, Westerholm P, Winter PD, Boffetta P (1999) Gender differences in the healthy worker effect among synthetic vitreous fiber workers. Am J Epidemiol 150 (10):1099-1106

Mapp CE, Boschetto P, Maestrelli P, Fabbri LM (2005) Occupational asthma. Am J Respir Crit Care Med 172 (3):280-305

Medina-Ramon M, Zock JP, Kogevinas M, Sunyer J, Torralba Y, Borrell A, Burgos F, Anto JM (2005) Asthma, chronic bronchitis, and exposure to irritant agents in occupational domestic cleaning: A nested case-control study. Occup Environ Med 62 (9):598-606

Modig L, Toren K, Janson C, Jarvholm B, Forsberg B (2009) Vehicle exhaust outside the home and onset of asthma among adults. Eur Respir J 33 (6):1261-1267

Reinisch F, Harrison RJ, Cussler S, Athanasoulis M, Balmes J, Blanc P, Cone J (2001) Physician reports of work-related asthma in california, 1993-1996. Am J Ind Med 39 (1):72-83

Rothman KJ, Greenland S (1998) Modern epidemiology. second edition edn. LippincottRaven, Philadelphia

Schatz M, Camargo CA, Jr. (2003) The relationship of sex to asthma prevalence, health care utilization, and medications in a large managed care organization. Ann Allergy Asthma Immunol 91 (6):553-558

Tarlo SM (2000) Workplace respiratory irritants and asthma. Occup Med 15 (2):471-484

Tarlo SM (2003) Workplace irritant exposures: Do they produce true occupational asthma? Ann Allergy Asthma Immunol 90 (5 Suppl 2):19-23

Taskinen TM, Laitinen S, Nevalainen A, Vepsalainen A, Meklin T, Reiman M, Korppi M, Husman T (2002) Immunoglobulin g antibodies to moulds in school-children from moisture problem schools. Allergy 57 (1):9-16

Toren K, Blanc PD (2009) Asthma caused by occupational exposures is common - a systematic analysis of estimates of the population-attributable fraction. BMC Pulm Med 9:7 